\title{
ЭКОНОМИЧЕСКАЯ ЭФФЕКТИВНОСТЬ ВОЗДЕЛЫВАНИЯ ПОДСОЛНЕЧНИКА В УСЛОВИЯХ ЛОКАЛЬНОГО ПРИМЕНЕНИЯ УДОБРЕНИЙ
}

\section{(c) 2021 Шитиков Никита Валерьевич}

аспирант

Курская Государственная сельскохозяйственная академия имени И.И.Иванова, Россия, Курск

E-mail: nikita_shitikov@inbox.ru

(c) 2021 Зайцева Наталья Валерьевна

аспирант

Курская Государственная сельскохозяйственная академия имени И. И. Иванова, Россия, Курск

E-mail:n.zaytseva@avgust.com

(c) 2021 Петрова Светлана Николаевна

доктор сельскохозяйственных наук

Курская Государственная сельскохозяйственная академия имени И.И.Иванова, Россия, Курск

E-mail: svet-orl@yandex.ru

\section{(c) 2021 Долгополова Наталья Валерьевна}

доктор сельскохозяйственных наук

Курская Государственная сельскохозяйственная академия имени И.И.Иванова, Россия, Курск

E-mail: dunaj-natalya@yandex.ru

(c) 2021 Трутаева Нина Николаевна

кандидат сельскохозяйственных наук

Курская Государственная сельскохозяйственная академия имени И.И.Иванова, Россия, Курск

E-mail: trutaeva_nn@kgsha.ru

(c) 2021 Зюкин Данил Алексеевич

кандидат экономических наук

Курская Государственная сельскохозяйственная академия имени И.И.Иванова, Россия, Курск

E-mail: nightingale46@rambler.ru

Рассматривается вопрос экономической целесообразности применения жидких комплексных удобрений в различных дозах при поверхностном их распределении и локальном способе внесения. Произведен расчет затрат на удобрения в зависимости от предложенных схем питания растений. Выявлено, что локальный способ внесения ЖКУ в среднем по вариантам способствовал увеличению доходности производства маслосемян в 3 раза, а каждый килограмм действующего вещества удобрений, при адресном применении в 4-6 раз эффективнее использовался растением на формирование урожая, обеспечивая дополнительный сбор 4,4-6,1 кг маслосемян с содержанием жира 4849\%. Предложено при использовании ЖКУ локальным способом сократить дозу удобрения на 50\%.

Ключевые слова: экономическая эффективность, подсолнечник, минеральные удобрения, локальное внесение, урожайность.

По данным Росстата общая площадь масличных культур в России к 2021 году выросла на 15\% - с 14,5 млн. га до 16,5 млн. га. При этом основной прирост был обеспечен за счет расширения посевов подсолнечника - только за год они увечились с 8,48 до 9,64 млн. га. [1]. Это не случайный факт, поскольку ежегодно закупочные цены на семена подсолнечника остаются высокими, что делает его высокорентабельной культурой в сравнении с другими сельскохозяйственными культурами.

В Курской области возделыванием подсолнечника по состоянию на 2020 год занималось 103 сельскохозяйственные организации, а общая посевная площадь этой культуры превысила 106 тыс. га. В регионе специализации в растениеводстве идет на возделывании зерновых культур, однако подсолнечник наряду с сахарной 
свеклой фабричной и соей является также важным элементом в структуре севооборота и экономической деятельности агробизнеса.

Средняя рентабельность возделывания подсолнечника в Курской области составляет почти 65\%, что существенно выше показателей по остальным сельскохозяйственным культурам, в том числе по зерновым, обуславливая заинтересованность агробизнеса. На долю убыточных сельскохозяйственных организаций приходится порядка 3\% в общем объеме посевов и валового сбора, тогда как остальные ведут рентабельное производство. Рентабельность свыше 30\%, что традиционно можно считать уровнем, обеспечивающим воспроизводство на расширенной основе, показывает более $90 \%$ сельскохозяйственных организаций, обрабатывающих 94,4\% посевов подсолнечника и собирающих 95,1\% валового сбора этой культуры (таблица 1).

Несмотря на высокую рентабельность, реализация высокой потенциальной продуктивности современных интенсивных гибридов подсолнечника сопряжена с достаточно высокими производственными затратами, в структуре которых влиятельную долю занимают расходы на обеспечение культуры элементами питания. При этом следует отметить, что цены на удобрения, особенно фосфорные, за последний год существенно возросли. По итогам 2020 года в структуре себестоимости доля расходов на минеральные удобрения свыше $20 \%$ была в группе сельскохозяйственных организаций, которыми собиралось 18,4\% валового сбора подсолнечника в области. Следует заметить, что для этой группы характерны самый высокий уровень урожайности и рентабельности, т.е. по факту они являются наиболее эффективными бизнес-субъектами, занимающихся возделыванием подсолнечника.
Минеральные удобрения показывают себя как приоритетный фактор повышения урожайности и экономической эффективности при возделывании основных сельскохозяйственных культур в области - зерна и сахарной свеклы фабричной [2, 3]. В контексте исследования процесса возделывания подсолнечника можно сделать вывод, что минеральные удобрения не показывают себя значимым фактором, так как стохастическая связь между затратами на них и урожайностью очень слабая (рисунок 1).

Уровень эластичности применения затрат под возделывание подсолнечника в регионе существенно меньше в сравнении с зерновыми культурами, где различными исследования доказывается их эффективность и высокая эластичность $[4,5]$. Причинами этого выступают: ценовая нестабильность минеральных удобрений и недостаток адаптированных к условиям района комбинаций применения семян и инструментов обогащения почв просто в силу меньшего опыта крупнотоварного производства подсолнечника в сравнении с зерновыми культурами и сахарной свеклой фабричной.

Одним из выходов в сложившейся ситуации может служить использование в производстве нетрадиционных форм минеральных удобрений с повышенным коэффициентом усвоения и пролонгированным действием, как жидкие комплексные удобрения (ЖКУ) и рациональное их использование. Например, локальнодифференцированный способ внесения удобрений позволяет значительно снизить затраты при увеличении эффективности каждого внесенного килограмма действующего вещества [6]. Происходит снижение расходов на удобрения и потерь элементов питания по сравнению с внесением усредненных доз минеральных удобрений по

Таблица 1. Распределение посевов и валового сбора подсолнечника по группам сельскохозяйственных организаций в зависимости от уровня рентабельности продаж в Курской области в 2020 г.

\begin{tabular}{|c|c|c|c|c|}
\hline \multirow{2}{*}{$\begin{array}{c}\text { Группы сельскохозяй- } \\
\text { ственных организаций по } \\
\text { уровню рентабельности } \\
\text { возделывания подсолнеч- } \\
\text { ника,\% }\end{array}$} & \multirow[b]{2}{*}{$\begin{array}{c}\text { Количество сельско- } \\
\text { хозяйственных ор- } \\
\text { ганизаций в группе }\end{array}$} & \multirow{2}{*}{$\begin{array}{c}\text { Средний уровень } \\
\text { рентабельности } \\
\text { продаж подсолнеч- } \\
\text { ника,\% }\end{array}$} & \multicolumn{2}{|c|}{ Доля в общем объеме } \\
\hline & & & $\begin{array}{c}\text { посевов подсолнеч- } \\
\text { ника,\% }\end{array}$ & $\begin{array}{c}\text { валового сбора под- } \\
\text { солнечника,\% }\end{array}$ \\
\hline Более 65 & 41 & 73,0 & 61,9 & 61,1 \\
\hline От 50 до 65 & 24 & 58,1 & 23,2 & 23,7 \\
\hline От 30 до 50 & 18 & 37,2 & 9,4 & 10,3 \\
\hline Менее 30 & 11 & 20,5 & 2,3 & 2,0 \\
\hline Убыточные & 9 & $-43,8$ & 3,3 & 2,9 \\
\hline Областное значение & 103 & 64,7 & 100,0 & 100,0 \\
\hline
\end{tabular}




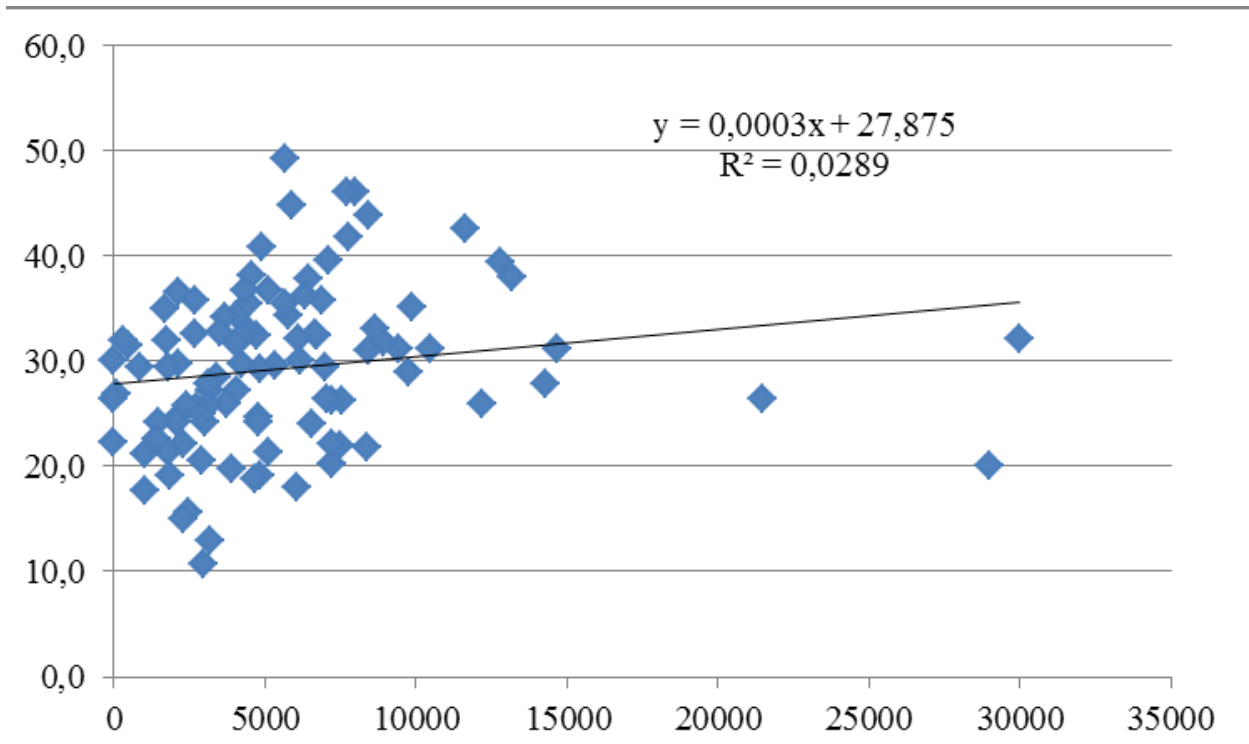

Puc. 1. Взаимосвязь урожайность подсолнечника и затрат на минеральные удобрения в сельскохозяйственных организациях Курской области в 2020 году

обычной методике, что не выравнивает «пестроты» полей. При этом на фоне положительного влияния на плодородие почвы и ее экологическое состояние, повышается урожайность и качество растениеводческой продукции. Сейчас, по оценке, проведенной аналитиками портала «Агроинвестор», подобные технологии в растениеводстве используют лишь около $10 \%$ российских аграриев. Вместе с тем, привлекательность локальнодифференцированного внесения удобрений, как и других технологических инноваций, определяется экономической эффективностью [7].

В этой связи цель нашего исследования состояла в оценке экономической целесообразности локально-дифференцированного способа внесения удобрений при возделывании такой высоко- энергетической культуры, как подсолнечник.

Объектом наших исследований являлся среднеспелый гибрид подсолнечника Неома селекции компании Syngenta, выращенный с использованием марки комплексных минеральных удобрений ЖКУ NP 11:37 производства ПАО «ФосАгро». Полевой опыт был заложен на опытном участке Курской ГСХА в Пристенском районе Курской области в 2020-2021 году по схеме двухфакторного опыта в четырехкратной повторности (таблица 2).

Для возделывания подсолнечника применялась технология общепринятая для данной зоны выращивания. Удобрения вносили в дозе 100 и 200 л/га (N8P26 и N16P52) сплошным и локальным способом. Для внесения удобрений ло-

Таблица 2. Оценка экономической эффективности способов применения ЖКУ при возделывании подсолнечника Неома

\begin{tabular}{|c|c|c|c|c|c|}
\hline Вариант & $\begin{array}{c}\text { Затраты на удо- } \\
\text { брения, руб./га }\end{array}$ & $\begin{array}{c}\text { Стоимость уро- } \\
\text { жая, руб./га }\end{array}$ & $\begin{array}{c}\text { Стоимость } \\
\text { прибавки } \\
\text { урожая, руб./ } \\
\text { га }\end{array}$ & $\begin{array}{c}\text { Дополнитель- } \\
\text { ный доход, руб./ } \\
\text { га }\end{array}$ & $\begin{array}{c}\text { Урожайность, } \\
\text { ц/га }\end{array}$ \\
\hline $\begin{array}{l}\text { 1. Контроль (фон NK) N60K90 } \\
+ \text { +Аммофос (N12 P52) }\end{array}$ & 9157 & 114100 & & - & 32,6 \\
\hline $\begin{array}{l}\text { 2. фон + ЖКУ NP 11:3) N8 } \\
\text { Р26(поверхностно) }\end{array}$ & 7631 & 115850 & 1750 & 3276 & 33,1 \\
\hline $\begin{array}{l}\text { 3. фон + ЖКУ NP 11:3) N16 P52 } \\
\text { (поверхностно) }\end{array}$ & 8652 & 119000 & 4900 & 5405 & 34,0 \\
\hline $\begin{array}{l}\text { 4. фон + ЖКУ NP 11:3) N8 P26 } \\
\text { (локально) }\end{array}$ & 7232 & 124600 & 10500 & 12425 & 35,6 \\
\hline $\begin{array}{l}\text { 5. фон + ЖКУ NP 11:3) N16 } \\
\text { Р52(локально) }\end{array}$ & 9367 & 128800 & 14700 & 14490 & 36,8 \\
\hline
\end{tabular}


кальным способом использовали аппликаторрастениепитатель RSM AF-3800 с заделкой удобрений на глубину 10 см.

Экономические расчеты в наших исследованиях показывают, что затраты на жидкие комплексные удобрения оказались меньше по сравнению с традиционно применяемыми в производстве гранулированными удобрениями. Внесенные в дозе N8 P26 жидкие удобрения обеспечили продуктивность подсолнечника сопоставимую с вариантом N12 P52 в гранулированной форме при затратах на удобрения на $16 \%$ меньше контрольного уровня (таблица 1). Следовательно, для получения урожайности подсолнечника 3,3 т/га целесообразно заменить гранулированные комплексные удобрения (аммофос) на жидкие (ЖКУ), что также подтверждается нашими работами на других культурах $[8,9]$.

Следует отметить, что продуктивность растений гибрида Неома при внесении ЖКУ поверхностным способом в зависимости от доз минеральных элементов существенно не изменилась, а дополнительный доход в данных вариантах не превышал 3,2-5,4 тыс. руб./га.

В тоже время выращивание подсолнечника при использовании локально-дифференцированного способа внесения ЖКУ в минимальной дозе позволило получить дополнительный экономический эффект 12,4 тыс. руб./га, как за счет сокращения затрат на удобрения, так и повышения продуктивности растений на 9\%. Максимальный экономический эффект был получен в варианте внесения N16 P52 локально, где при сопоставимых с контрольным уровнем затратах на удобрения и уровне продуктивности 3,7 т/га выручка возросла до 14,5 тыс. руб./га.

При этом каждый кг действующего вещества удобрений обеспечивал дополнительную прибавку урожая в размере $4,4-6,1$ кг, что в 3,2 раза выше, чем при поверхностном распределении удобрений (рисунок 2).

Таким образом, лучшая доступность питательных веществ при локальном способе локальный способ внесения ЖКУ в среднем по вариантам способствовал увеличению доходности производства маслосемян в 3 раза, а каждый килограмм действующего вещества удобрений, при адресном применении в 4-6 раз эффективнее использовался растением на формирование урожая, обеспечивая дополнительный сбор 4,46,1 кг маслосемян с содержанием жира 48-49\%. Следовательно, с точки зрения экономической эффективности производства подсолнечника при использовании ЖКУ локальным способом целесообразно сократить дозу удобрения на 50\%.

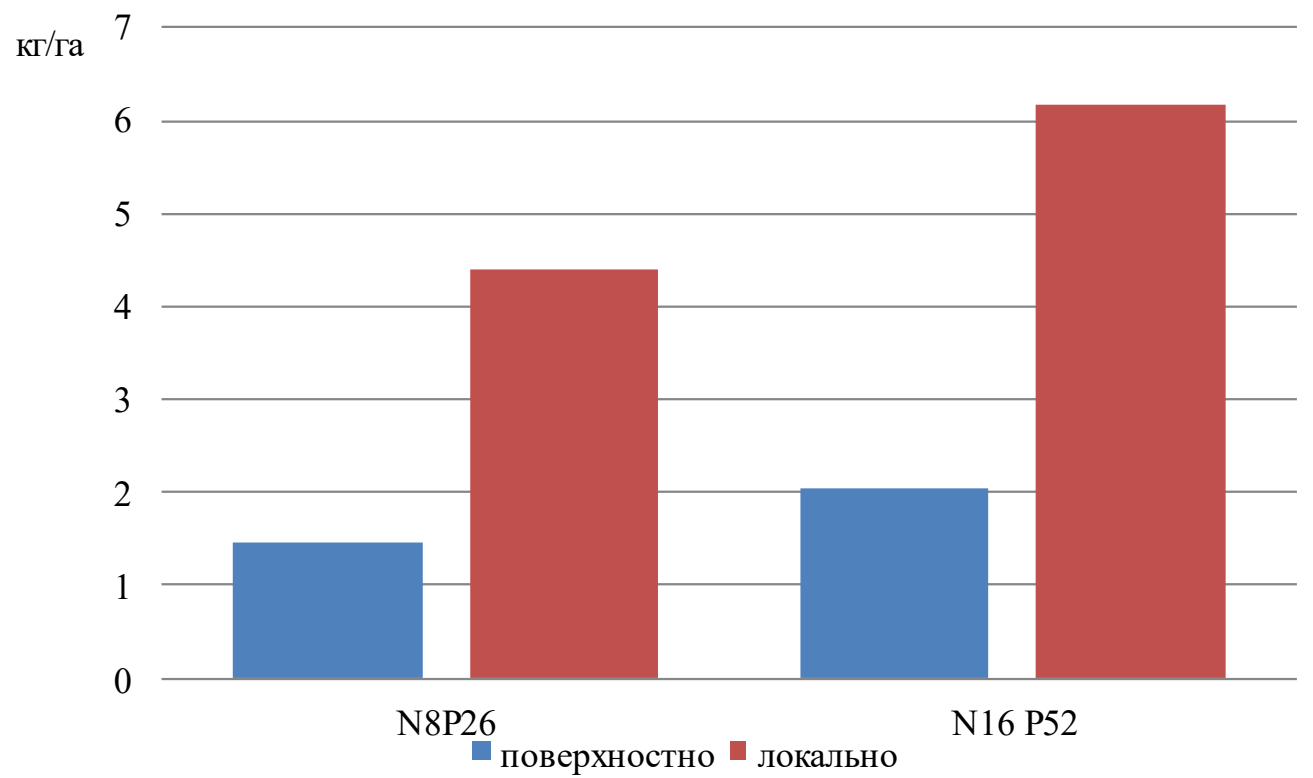

Puс. 2. Эффективность удобрений (кг) от применения 1 кг д.в. в схеме питания 


\section{Библиографический список}

1. Белая А., Шокурова Е. Доход останется в масличных. // Агроинвестор. № 9. 2021. С. 42-49.

2. Оценка влияния факторов на эффективность выращивания сахарной свеклы в Курской области / О.В. Святова, Д.А. Зюкин, С. А. Быканова, О. Н. Горяинова // Сахарная свекла. 2013. № 10. С. 7-9.

3. Зюкин Д.А., Солошенко Р.В. Оценка направлений интенсификации как условия повышения результативности и эффективности производства зерна // Вестник Курской государственной сельскохозяйственной академии. 2019. № 8. С. 198-203.

4. Статистические методы в оценке эффективности использования затрат на производство зерна / Т.Н. Соловьева, Д. А. Зюкин, Н. А. Пожидаева, В. В. Жилин // Международный журнал прикладных и фундаментальных исследований. 2015. № 10-4. С. 707-710.

5. Зюкин Д.А.Интенсификация как условие реализации производственно-экономического потенциала зернового хозяйства // Международный сельскохозяйственный журнал. 2018. № 6. С. 42-45.

6. Чекмарев П.А., Лукманов А. А. Освоение элементов точного земледелия в практической агрохимии республики Татарстан // Достижения науки и техники АПК. № 03. 2011. С. 3-4.

7. Эффективность точного земледелия на выщелоченном черноземе Воронежской области / В.И. Корчагин, Ю.А. Кошелев, Н.Г. Мязин, Р.Н.Ратников // Вестник Воронежского государственного аграрного университета. 2016. № 1(48). С. 17-23.

8. Эффективность подкормок озимой пшеницы различными марками азотных и комплексных удобрений / В. В. Мамеев, В.Е. Ториков, С.Н. Петрова, Д. В. Дубинин, Л. М. Гааб // Вестник Курской государственной сельскохозяйственной академии. 2021. № 6. С. 12-19.

9. Оценка эффективности применения комплексных удобрений при возделывании кукурузы на зерно / О.А.Нестеренко, А.В.Дронов, В.В.Мамеев, С.Н.Петрова, А.А.Лукашина // Вестник Курской государственной сельскохозяйственной академии. 2021. № 6. С. 20-27. 